\title{
Perspectives of Young Otolaryngologists on Pediatric ENT and the Future of the Field in Turkey
}

\author{
Original Investigation $>$ Nesrettin Fatih Turgut ${ }^{1}$ (D), Doğukan Özdemir ${ }^{1}$ (D), Dursun Mehmet Mehel ${ }^{1}$ (D), Gökhan Akgül ${ }^{1}$ (D), \\ Abdulkadir Özgür ${ }^{1}$ (D), Suat Turgut ${ }^{2}$ \\ ${ }^{1}$ Department of Otorhinolaryngology, University of Health Sciences, Samsun Health Practices and Research Center, Samsun, Turkey \\ ${ }^{2}$ Department of Otorhinolaryngology, University of Health Sciences, Hamidiye Etfal Health Practices and Research Center, \\ İstanbul, Turkey
}

Abstract

ORCID iDs of the authors: N.F.T. 0000-0001-6265-0058; D. $0.0000-0003-2008-163 X_{\text {; }}$ D.M.M. 0000-0002-5613-3393; G.A. 0000-0003-0699-6585; A.0̈.0000-0002-6155-5988; S.T. $0000-0001-9364-2149$.

Cite this article as: Turgut NF, Özdemir D, Mehel DM, Akgül G, Özgür A, Turgut S. Perspectives of Young Otolaryngologists on Pediatric ENT and the Future of the Field in Turkey. Turk Arch Otorhinolaryngol 2020; 58(3): 163-8.

\section{Corresponding Author:}

Nesrettin Fatih Turgut, drnesrettinfatih@gmail.com

Received Date: 30.05 .2020 Accepted Date: 30.06 .2020

Content of this journal is licensed under a Creative Commons Attribution 4.0 International License. Available online at www.turkarchotolaryngol.net
Objective: The purpose of this study was to examine the current status and the future of pediatric otolaryngology in Turkey by evaluating the opinions of young otolaryngologists on pediatric otolaryngology.

Methods: The study included 224 otolaryngology physicians who were senior residents registered with the Turkish Otolaryngology and Head-Neck Surgery Association (TORL-HNS). The physicians were in their last two years of otolaryngology training (154 physicians) or had completed their residency training and were in their first year of otolaryngology practice (70 physicians). They were approached via e-mail and Short Message Service (SMS) in October through December 2019 with a descriptive letter and asked to voluntarily complete an online questionnaire consisting of total 25 questions in five sections.

Results: The online questionnaire was sent to 224 physicians, and 109 (49\%) participated in the survey. All 109 participants answered all the questions. Overall, 71 participants $(65.1 \%)$ were in training for residency and 38 (34.9\%) were in their first year of ex-

\section{Introduction}

In general Ear, Nose and Throat (ENT) practice $30-35 \%$ of the examined patients are from the pediatric patient group (1). In our country and in some developed countries, the number of physicians who exclusively treat pediatric patients is very limited; in general, it is the general ENT specialists who evaluate all patients regardless of their age, whether pediatric or adult (2).

Pediatric otolaryngology has progressed rapidly as a subspecialty of ENT in the last decade. The development of this field first began in the United States, led by the efforts of Charles Ferguson pertise. According to their professional interests, the participants listed rhinology (45 participants, 41.3\%), head and neck surgery (27 participants, $24.8 \%$ ), facial plastic surgery (19 participants, 17\%), otology-neurotology (16 participants, 14.7\%), and laryngology-phoniatry ( 2 participants, $1.8 \%$ ) as their first preference for subspecialty. Pediatric otolaryngology was never a first choice among the participants, although four (3.7\%) listed pediatric otolaryngology as their second preference.

Conclusion: The aim of this study was to shed light on the current and future status of pediatric otolaryngology in Turkey. We believe the establishment of exclusive pediatric otolaryngology clinics under the umbrella of general ear, nose and throat (ENT) clinics and the foundation of officially approved fellowship programs would bring this subspecialty field to its deserved and desired level in our country.

Keywords: Pediatric otolaryngology, fellowship, education, subspecialty, residency
(1933-1974) who worked as a full-time pediatric otolaryngologist. After the first fellowship program was founded in 1975 in the USA and approved by the Accreditation Council for Graduate Medical Education in 1998 in 1998, training processes for this subspecialty after residency advanced significantly (3). Two countries in Europe approved pediatric otolaryngology as an official subspecialty field in medical practice: Hungary opened its first pediatric otolaryngology clinic in 1952, and Poland's government approved pediatric otolaryngology as an official medical subspecialty in 1958 (4). In Turkey, however, pediatric otolaryngology has not yet been officially approved, and the number of physicians 
who are specifically interested in this field is quite limited. These few physicians generally work as faculty members in the pediatric otolaryngology outpatient clinics connected to the ear, nose, and throat (ENT) clinics of university research hospitals. There are, however, no approved fellowship training programs for any ENT subspecialty in our country for further training after residency. In the coming years, some ENT specialists will surely dedicate their efforts to this field and ensure the development of this subspecialty. Preciado et al. (2) also drew attention to this issue.

Given the rapid development of pediatric otolaryngology in some developed countries, it is worth examining the potential process of this field in Turkey. The presented study evaluates the opinions of young ENT specialists along their path to transitioning to subspecialty fields based on their skills and professional interests; and discusses the current status and the guiding data for the future of pediatric otolaryngology in Turkey.

\section{Methods}

Ethics committee approval was received for this study from the Ethics Committee of University of Health Sciences Samsun Training and Research Hospital Non-Interventional Clinical Trials (Approval Date: September 26, 2019; Approval Number: KAEK 2019/4/29).

A total of 224 otolaryngology specialists (154 senior residents and 70 expert specialists), including senior residents registered with the Turkish Otolaryngology and Head-Neck Surgery Association (TORL-HNS) were surveyed. The participants were either in their last two years of otolaryngology training or expert physicians who had completed their residency training and were in their first year in the field. All were contacted via e-mail and Short Message Service (SMS) in October 2019 to December 2019 and sent a descriptive letter about the study. They were asked to complete an online questionnaire on a voluntary basis (Google Surveys; California, USA). The questionnaire was written in Turkish language and consisted of 25 questions in total in five sections. Participants were also asked to fill-out the online informed consent form. The response time was set as eight weeks. The first section of the survey queried the participants about their demographic characteristics (age, gender, the city where they received their residency education). The second section asked about participants' preferences for a subspecialty, while the third section asked whether there

\section{Main Points}

- Unsurprisingly, pediatric otolaryngology is not a preferred subspecialty field for most young ENT surgeons because of economic reasons or the absence of pediatric otolaryngologists in their department.

- Pediatric otolaryngology fellowship training programs offered at children's hospitals along with all pediatric surgical departments at academic levels will inevitably influence young surgeons in the positive direction.

- It is necessary to improve this field by establishing new fellowship programs in our country. Therefore, we believe that the Turkish Pediatric Otolaryngology Society has a tremendous responsibility in developing this subspecialty professionally. were any faculty members specialized in pediatric otolaryngology in the center they did their residency training and the outpatient clinic experience of the participants. The fourth section asked the participants about their scientific research in pediatric otolaryngology and whether they were a member of the Turkish Pediatric Otolaryngology and Head-Neck Surgery Association or any other relevant international associations. The questions in the fifth section addressed the clinical experience of the participants in the field of pediatric otolaryngology and the number of pediatric surgeries performed in their clinics. The English translation of the questionnaire is given in Appendix 1. The survey responses were collected in a central online database (Google Drive; California, USA) and recorded using Microsoft Excel (Microsoft; Seattle, USA). Statistical data, including mean values, proportions, and standard deviations, were calculated using Microsoft Excel 2010.

\section{Results}

The online survey was sent to a total of 224 physicians of whom 109 (49\%) responded to the survey. All physicians who participated in the survey answered all the questions. Of the 109 participants, $71(65.1 \%)$ were in training for residency, while the remaining $38(34.9 \%)$ were in their first year of expertise; 37 (33.9\%) were female and 72 (66.1\%) were male. Their mean age was $30.2 \pm 1.7$ (25-34) years. The demographic characteristics of the participants are given in Table 1 . The majority of the participating physicians $(60 \%)$ had completed their specialty training in one of the three largest cities in Turkey: 37 (34\%) in İstanbul, $18(16 \%)$ in Ankara, and 11 (10\%) in İzmir. The remaining 44 (40\%) did their training in other smaller cities.

The physicians were asked to rank their preferences for a subspecialty according to their professional interest. While 45 participants (41.3\%) ranked rhinology, 27 (24.8\%) head-neck surgery, 19 (17\%) facial plastic surgery, 16 (14.7\%) otology-neurotology, and two (1.8\%) laryngology-phoniatry as their first preference for a subspecialty. None of the participants indicated pediatric otolaryngology as their first preference, but four (3.7\%) listed as their second preference. Table 2 shows the ratios for field preference rankings. Forty-three participants (39.4\%) answered "yes" to the question of whether there were any faculty members specialized in pediatric otolaryngology in the center they did their residency training. Only 18 participants $(16.5 \%)$ stated that they

Table 1. Demographic characteristics of participants

\begin{tabular}{l|l|c}
\hline Age Mean \pm SD $(\min -m a x)$ & \multicolumn{2}{|c}{$30.2 \pm 1.7(25-34)$} \\
\hline \multirow{2}{*}{ Gender $(n / \%)$} & Female & $37 / 33.9$ \\
\cline { 2 - 3 } City of residency (n/\%) & Male & $72 / 66.1$ \\
\hline & İstanbul & $37 / 34$ \\
\cline { 2 - 3 } & Ankara & $18 / 16$ \\
\cline { 2 - 3 } & İzmir & $11 / 10$ \\
\cline { 2 - 3 } & Other & $44 / 40$ \\
\hline \multirow{2}{*}{ Position (n/\%) } & Resident in $4^{\text {th }}$ year & $45 / 41.3$ \\
\hline & Resident in $5^{\text {th }}$ year & $26 / 23.9$ \\
\hline & $1^{\text {st }}$ year in specialty & $38 / 34.9$ \\
\hline
\end{tabular}


had worked in an exclusively pediatric outpatient clinic during their residency training.

The responses to the questions about memberships in national or international pediatric otolaryngology associations, participations in conferences, and participation in a journal club or study groups related to the field are given in Table 3. Nine participants (8.3\%) stated they had previous knowledge about the Turkish Pediatric Otolaryngology and Head-Neck Surgery Association, while only one participant $(0.01 \%)$ stated to be a registered member of this association. Only one participant $(0.09 \%)$ had international experience in this field. Eighty-two participants (75.2\%) replied "yes" to the question of whether they would be interested in participating in a fellowship training program in this field. The participants indicated head and neck mass excision (45\%) and midd-

Table 2. Subspecialty fields; ranking of first three preferences

\begin{tabular}{l|c|c|c}
\hline ENT subspecialty fields & $\begin{array}{c}\mathbf{1}^{\text {st }} \text { choice } \\
\mathbf{n} / \%\end{array}$ & $\begin{array}{c}\mathbf{2}^{\text {nd }} \text { choice } \\
\mathbf{n} / \%\end{array}$ & $\begin{array}{c}3^{\text {rd }} \text { choice } \\
\mathbf{n} / \%\end{array}$ \\
\hline Rhinology & $45 / 41.3$ & $29 / 26.6$ & $15 / 13.6$ \\
\hline Head-neck surgery & $27 / 24.8$ & $16 / 14.7$ & $18 / 16.5$ \\
\hline Facial plastic surgery & $19 / 17.4$ & $27 / 24.8$ & $13 / 11.9$ \\
\hline Otology-neurotology & $16 / 14.7$ & $26 / 23.9$ & $35 / 32.1$ \\
\hline Laryngology-phoniatry & $2 / 1.8$ & $7 / 6.4$ & $14 / 12.8$ \\
\hline Pediatric otolaryngology & $0 / 0$ & $4 / 3.7$ & $14 / 12.8$ \\
\hline
\end{tabular}

le ear surgery (45\%) as the most frequently performed surgical procedures in patients under the age of 15 at the clinics where the participants did their training. Direct laryngoscopy (38.5\%) and endoscopic or open technique airway surgery (40.4\%) were reported as the least frequently performed surgical procedures in pediatric patients. Overall, the least frequently performed surgical procedures were endoscopic or open airway surgery (23.8\%) and direct laryngoscopy (31.2\%). The numbers and the ratios of the surgical procedures are given in Table 4.

\section{Discussion}

Pediatric otolaryngology, as a subspecialty that falls under the umbrella of otolaryngology and the head-neck surgery, has increasingly gained importance and developed in the recent years. In 1975, the first fellowship training program in pediatric otolaryngology was founded in USA by Dr. Bluestone and Dr. Sto$\mathrm{ol}$ and the program was approved by the Accreditation Council for Graduate Medical Education in 1998 (3). Dr. Trevor McGill and Dr. Gerald Healy at the Children's Hospital Boston, and Dr. Robin Cotton pioneering pediatric airway surgery, at the Cincinnati Children's Hospital Medical Center established fellowship positions in their respective institutions (5). With these steps forward, the field became a separate subspecialty one, and developed countries are now organizing related fellowship training programs after medical specialty training. Fellowship training programs are offered for 12-24 months at selected pediatric hospitals in the UK, Canada, and Australia. In addition to

Table 3. Scientific activities of participants in pediatric otolaryngology

\begin{tabular}{l|c|c|}
\hline & Yes (n/\%) & No $(\mathrm{n} / \%)$ \\
\hline Have you read an up-to-date pediatric otolaryngology guideline within the last year? & $59 / 54.1$ & $50 / 45.9$ \\
\hline Have you read any articles on pediatric otolaryngology in the last six months? & $67 / 61.5$ & $42 / 38.5$ \\
\hline Have you participated in a working group related to pediatric otolaryngology in the last six months? & $97 / 89$ & $12 / 11$ \\
\hline Do you have experience abroad in pediatric otolaryngology? & $108 / 99.1$ \\
\hline Would you like to participate in a pediatric otolaryngology fellowship program? & $27 / 24.8$ \\
\hline Are you familiar with the Turkish Pediatric Otolaryngology and Head-Neck Surgery Association? & 10.09 & $92 / 75.2$ \\
\hline Are you a member of the Turkish Pediatric Otolaryngology and Head-Neck Surgery Association? & $100 / 91.7$ \\
\hline Are you a member of any international associations related to pediatric otolaryngology (ESPO, ASPO, ANZSPO, others)? & $0 / 0$ & $109 / 10.01$ \\
\hline Have you attended the National Pediatric Otolaryngology meeting? & 109.1 \\
\hline Have you attended an international pediatric otolaryngology meeting? & $109 / 100$ \\
\hline
\end{tabular}

ESPO: European Society of Pediatric Otolaryngology; ASPO: American Society of Pediatric Otolaryngology; ANZSPO: The Australian and New Zealand Society of Paediatric Otorhinolaryngology

Table 4. Clinical cases of patients under 15 years of age observed by participants in one year

\begin{tabular}{l|c|c|c|c}
\hline & None & $\mathbf{1 - 5}$ cases & $\mathbf{6 - 1 0}$ cases & $\mathbf{1 1}$ or more cases \\
\hline Flexible endoscopy & $4.6 \%$ & $0.9 \%$ & $8.3 \%$ & $\mathbf{1 1 \%}$ \\
\hline Emergency or elective tracheotomy & $26.6 \%$ & $28.5 \%$ & $17.4 \%$ & $33.9 \%$ \\
\hline Head/neck mass excision & $11.9 \%$ & $25.7 \%$ & $6.4 \%$ & $31.2 \%$ \\
\hline Direct laryngoscopy & $38.5 \%$ & $23.9 \%$ & $11.9 \%$ & $23.8 \%$ \\
\hline Endoscopic or open airway surgery & $40.4 \%$ & $23.9 \%$ & $15.6 \%$ & $15.6 \%$ \\
\hline Otoplasty & $17.4 \%$ & $51.4 \%$ & $20.2 \%$ & $45 \%$ \\
\hline Middle ear surgery & $9.2 \%$ & $25.6 \%$ & & \\
\hline
\end{tabular}


physicians who complete their fellowship education in the United States, physicians who devote a certain proportion of their clinical practice to pediatric patients also identify themselves as pediatric otolaryngology specialists (2). In the UK, pediatric otolaryngology is a subspecialty of particular interest for both general otolaryngology specialists and specialists with pediatric otolaryngology fellowship training (1). By contrast, Turkey has no officially approved pediatric otolaryngology fellowship training centers, and the number of physicians working as full-time pediatric otolaryngology specialists is very limited.

A study in 2009 by Preciado et al. (2) reported that 98\% of pediatric otolaryngology physicians, especially those who had completed fellowship training, worked in cities with populations of over one million. In 2005, the Netherlands had only three pediatric otolaryngology specialists who exclusively worked with pediatric patients, and all three worked in large cities (6). Likewise, in Turkey, full-time pediatric otolaryngology specialists generally work in large cities. It is clear that pediatric ENT departments can only be established in pediatric centers accommodating all necessary surgical specialties dedicated to childcare. Adequate pediatric centers in Turkey are generally part of university hospitals in large cities. In our study, 43 participants (39.4\%) answered "yes" to the question about the presence of a faculty member specialized in pediatric otolaryngology in their clinic. Of these 43 participants, 32 (76\%) were physicians who had completed their specialty training in major cities.

The rates of participation in the surveys conducted in the pediatric otolaryngology field were reported as $60.8 \%$ by Osman et al. (1), $39.3 \%$ by Preciado et al. (2), $26 \%$ by Kerscher et al. (7), and $49 \%$ by Bell et al. (8). Comparably, the participation rate in our study was $49 \%$.

The practice of otolaryngology involves the treatment of pediatric patients, but a certain level of attention is required in some complicated diseases such as congenital anomalies, airway problems, and vestibular diseases. A survey study conducted by Bell et al. (8) showed that $64 \%$ of the participants reported working in medical schools or university hospitals. Pediatric otolaryngologists are generally concentrated in cities with high population density $(2,9)$. In our study, we found that the clinics that have faculty members specializing in pediatric otolaryngology were also located in large cities with high population densities. Since complicated cases are therefore referred to third-level medical centers in major cities, residents working in smaller centers are less likely to gain experience in such rare cases. This situation is also emphasized by Alberti. (10).

A survey conducted with 332 general otolaryngology physicians in the UK reported that $42 \%$ of the participants indicated a special interest in pediatric otolaryngology (1). In their study, Kerscher et al. (7) reported that $93 \%$ of the residents' clinics had exclusive pediatric otolaryngology faculty members and that $27 \%$ had specialists with pediatric otolaryngology fellowships. The presence of specialists in subspecialty fields had a positive impact on the residents, and $16 \%$ of the senior resident physicians stated that they would like to receive pediatric otolaryngology fellowship training after their residency training. Furthermore, $87 \%$ of the residents reported their satisfaction with their pediatric otolaryngology training (7). A 1994 study by Miller (11) reported the level of satisfaction at $60 \%$ among residents. In our study, only $39 \%$ of the participants reported the presence of a faculty member specialized in pediatric otolaryngology in their clinics.

Ranking of the interests in a subspecialty field also revealed that pediatric otolaryngology was never the first preference, although four participants (3.7\%) ranked this field as their second choice and $14(12.8 \%)$ ranked as their third. The reasons for not preferring pediatric otolaryngology in Turkey may be correlated with the state healthcare system and its economic impact on junior ENT surgeons. Majority of the doctors are paid based on "performance points" and remunerations are calculated based on the number of patients examined and surgeries performed. Therefore, it is understandable for junior ENT surgeons to have a tendency for other subspecialties that provide better reimbursement.

In our study, only $16 \%$ of the 18 participants who listed pediatric otolaryngology among their preferred subspecialties also had an exclusive pediatric otolaryngology faculty member in their respective centers. Contrary to the study of Kerscher et al. (7), the presence of faculty members specialized in this field does not seem to have a positive impact on the career planning of residents in our country.

A study conducted in the UK found that $81 \%$ of otolaryngology specialists felt that pediatric otolaryngology should be approved as an official subspecialty with a training period of at least six months (1). Hoeve (6) stressed the need to establish pediatric otolaryngology fellowship training programs in order to train quality subspecialty experts in The Netherlands. In the study by Bell et al. (8), pediatric otolaryngology specialists were reported to have a fellowship training period of 12 to 24 months, and $94 \%$ of the physicians found this time adequate. In Turkey, there are no centers that provide an approved pediatric otolaryngology fellowship training program. Interestingly, although 18 individuals in our study listed pediatric otolaryngology as their second or third preferred subspecialty, 82 physicians (75.2\%) stated that they would like to participate in a pediatric otolaryngology fellowship program.

A study by Erdağ et al. (12) reviewed the numbers of pediatric otolaryngology articles from Turkey published in SCI-listed (Science Citation Index) journals in 1995, 2000, 2005, 2010 and 2012, and compared these with those from other European countries. In the studied four years $(2000,2005,2010$, and 2012), Turkey had the highest number of published pediatric otolaryngology articles compared to other European countries (12). In our study, $89 \%$ of the participants stated that they did not partake in a study related to pediatric otolaryngology in the last six months. When asked whether they had read an up-todate guideline on pediatric otolaryngology in the past one year 
or had read a publication on pediatric otolaryngology in the last six months, $54.1 \%$ and $61.5 \%$ of the participants, respectively, responded "yes." Remarkably, young physicians are far from following up on the recent advancements in this field, despite the scientific productivity related to this subspecialty in our country in the recent years.

In the UK, general otolaryngology specialists rather focus on upper airway infections, such as tonsillitis, adenoiditis, and sinusitis, and on ear pathologies, such as otitis media with effusion $(1,3)$. In the study by Preciado et al. (2) respondents reported the that they mostly managed general otolaryngology cases, such as adenoidectomy, tonsillectomy, and tube application in their practice (48.8\%), pediatric airway cases (17.2\%) and otology cases (9.8\%). Pediatric otolaryngology specialists who completed their fellowship training and were employed in the academia emphasized that they, unlike other physicians, encountered choanal atresia surgeries and complex comorbid patients more frequently. In the study by Kerscher et al. (7), senior residents reported that they were more comfortable with the clinical management of upper airway pathologies, adeno-tonsillar diseases, otitis media, sinusitis, stridor, and congenital hearing loss, as well as adenotonsillectomy, myringotomy, and laryngoscopy surgery. By contrast, they reported not having sufficient experience in the medical management of craniofacial anomalies, laryngotracheal stenosis reconstructions, and the surgical management of velopharyngeal insufficiency (7).

The case-based questions in our survey addressed physical examination and surgical approaches in the clinic. The number and the variety of cases are important parameters for young physicians to demonstrate their experience. Head and neck mass excision and middle ear surgery were reported as the most frequent procedures performed by the participants in their clinics. The study conducted by Côté et al. (13) reported that resident physicians in Canada did not receive sufficient training in the management of challenging airway cases, and thereby felt inadequate, especially when treating pediatric patients. When frequently applied surgical approaches were evaluated, direct laryngoscopy and endoscopic or open airway surgery were the least frequently applied surgeries in a year, i.e., $31.2 \%$ and $23.8 \%$, respectively. The rates of those who stated that these surgical approaches were never applied in their clinics were $38.5 \%$ and $40.4 \%$ for direct laryngoscopy and airway surgeries, respectively. These procedures were indicated as the least commonly applied surgeries. The data obtained in the presented study were also consistent with those from the study by Côté et al. (13), which suggests that the establishment of pediatric otolaryngology subspecialty training programs help to eliminate the issues of young physicians who feel inadequate and uncomfortable in this field.

Our study is the first study to evaluate the opinions of young otolaryngology physicians regarding the pediatric otolaryngology subspecialty field in Turkey, and the results should shed light on the future of this field. Our study was conducted with participation rates comparable to those of other studies reported in the literature; yet we deem that the inability to reach all physicians in the field is a disadvantage of our study. A further limitation is the evaluation of pediatric otolaryngology education without sufficient knowledge about the technical infrastructure and multidisciplinary working opportunities of the centers in which the participants were working at the time of the survey.

\section{Conclusion}

Pediatric otolaryngology is an advanced subspecialty within otolaryngology with approved fellowship programs in some developed countries. The aim of the presented study was to shed light on the existing state and the near-future prospect of pediatric otolaryngology in Turkey. Our findings indicate that setting-up subspecialty clinics and building approved fellowship programs in otolaryngology clinics will bring pediatric otolaryngology to its desired and expected level in our country. The results also emphasize the importance of conducting additional studies to address various viewpoints and solution ideas.

Ethics Committee Approval: Ethics committee approval was received for this study from the Ethics Committee of University of Health Sciences Samsun Training and Research Hospital Non-Interventional Clinical Trials (Approval Date: September 26, 2019; Approval Number: KAEK 2019/4/29).

Informed Consent: Informed consent was obtained from the patients who participated in this study.

Peer-review: Externally peer-reviewed.

Author Contributions: Concept - N.F.T.; Design - N.F.T., A.Ö.; Supervision - A.Ö., S.T.; Data Collection and/or Processing - N.F.T., D.Ö.; Analysis and/or Interpretation - D.Ö.; Literature Search D.M.M., G.A.; Writing - N.F.T., D.M.M.; Critical Reviews - A.Ö., S.T.

Conflict of Interest: The authors have no conflicts of interest to declare.

Financial Disclosure: The authors declared that this study has received no financial support.

\section{References}

1. Osman EZ, Aneeshkumar MK, Clarke RW. Paediatric otolaryngology services in the UK: a postal questionnaire survey of ENT consultants. J Laryngol Otol 2005; 119: 259-63. [Crossref]

2. Preciado D, Tunkel D, Zalzal G. Pediatric otolaryngology in the United States: demographics, workforce perceptions, and current practices. Arch Otolaryngol Head Neck Surg 2009; 135: 8-13. [Crossref]

3. Cunningham MJ, Lin AC. Pediatric otolaryngology: the maturation of a pediatric surgical subspecialty. Laryngoscope 2011; 121 : 194-201. [Crossref]

4. Verwoerd C, Froehlich P, Gryczynska D, Katona G, Pitkaranta A, Blayney A. Pediatric otorhinolaryngology anno 2008: towards European standards for training? Int J Pediatr Otorhinolaryngol 2009; 73: 839-41. [Crossref]

5. Ruben RJ. Development of pediatric otolaryngology in North America. Int J Pediatr Otorhinolaryngol 2009; 73: 541-6. [Crossref]

6. Hoeve HLJ. Paediatric otorhinolaryngology in the Netherlands. Clin Otolaryngol 2005; 30: 98. [Crossref] 
7. Kerscher K, Tabaee A, Ward R, Haddad Jr J, Grunstein E. The residency experience in pediatric otolaryngology. Laryngoscope 2008; 118: 718-22. [Crossref]

8. Bell JR, Ruch-Ross H, Hotaling AJ. Practice patterns and projections for the US pediatric otolaryngology workforce. JAMA Otolaryngol Head Neck Surg 2016; 142: 823-7. [Crossref]

9. Stoddard JJ, Cull WL, Jewett EAB, Brotherton SE, Mulvey HJ, Alden ER. Providing pediatric subspecialty care: a workforce analysis. Pediatrics 2000; 106: 1325-33. [Crossref]

10. Alberti PW. Pediatric ear, nose and throat services' demands and resources: a global perspective. Int J Pediatr Otorhinolaryngol 1999; 49: S1-9. [Crossref]
11. Miller RH. Otolaryngology residency and fellowship training. The resident's perspective. Arch Otolaryngol Head Neck Surg 1994; 120: 1057-61. [Crossref]

12. Erdağ TK, Durmuşoğlu M, Özay H, Sönmez F, Doğan E. [Turkey's place in Europe in respect of pediatric otorhinolaryngology publications in scope of Science Citation Index]. Kulak Burun Boğaz Ihtis Derg 2015; 25: 163-9. [Crossref]

13. Côté V, Kus LH, Zhang X, Richardson K, Nguyen LHP. Advanced airway management teaching in otolaryngology residency programs in Canada: a survey of residents. Ear Nose Throat J 2015; 94: 187-92. 
Appendix 1. English translation of the questions asked in the survey "Future of Pediatric Otolaryngology"

\section{Section 1. Demographic characteristics}

1. Age

2. Gender

3. The city where you had/have your residency training

4. Position

Senior resident/Specialist in first year

\section{Section 2. Subspecialty preferences}

5. Your preference for subspecialty in ENT-first choice?

6. Your preference for subspecialty in ENT-second choice?

7. Your preference for subspecialty in ENT-third choice?

\begin{tabular}{|ll|}
\hline 1. & Otology \\
\hline 2. & Rhinology \\
\hline 3. & Head neck surgery \\
\hline 4. & Pediatric otolaryngology \\
\hline 5. & Facial plastic surgery \\
\hline 6. & Laryngology and phoniatry \\
\hline 1. & Otology \\
\hline 2. & Rhinology \\
\hline 3. & Head neck surgery \\
\hline 4. & Pediatric otolaryngology \\
\hline 5. & Facial plastic surgery \\
\hline 6. & Laryngology and phoniatry \\
\hline 1. & Otology \\
\hline 2. & Rhinology \\
\hline 3. & Head neck surgery \\
\hline 4. & Pediatric otolaryngology \\
\hline 5. & Facial plastic surgery \\
\hline 6. & Laryngology and phoniatry \\
\hline
\end{tabular}

Section 3. The presence of faculty members specialized in pediatric otolaryngology in their clinics and the outpatient clinic experience of participants

8. During your residency training, have you worked in an outpatient clinic that exclusively treatspediatric patients? If yes, for how long?

9. Is there a faculty member (Professor, Associate Professor, Resident Professor) specialized in pediatric otolaryngology in the center you had/have your residency training? 
Turgut et al.

Section 4. Scientific activities related to pediatric otolaryngology, membership in Turkish Pediatric Otolaryngology and Head-Neck Surgery Association or other international associations

10. During your residency training, have you attended a national or international conference on pediatric otolaryngology?

11. If yes, please write the name/s of the conference/s?

12. During the past one year, have you read an up-to-date guideline on pediatric otolaryngology?

13. During the last six months, have you read any scientific articles on pediatric otolaryngology?

14. During the last six months, have you participated in a working group related to pediatric otolaryngology?

15. Are you familiar with the Turkish Pediatric Otolaryngology and Head-Neck Surgery Association?

16. Are you an official member of any national or international associations for pediatric otolaryngology? If yes, please provide the name/s of the association/s.

Yes/No

Yes/No

Yes/No

$\mathrm{Yes} / \mathrm{No}$

No

Turkish Pediatric Otolaryngology and Head-Neck Surgery Association

European Society of Pediatric

Otolaryngology (ESPO)

American Society of Pediatric

Otolaryngology (ASPO)

Other

17. Do you have any experience abroad related to the pediatric otolaryngology subspecialty field?

Yes/No

18. Would you be interested in participating in a fellowship program in the pediatric otolaryngology subspecialty field? Yes/No

Section 5. Clinical experience in pediatric otolaryngology and number of surgical approaches performed in their clinics

19. In your clinic, how many cases were there in a year that involved patients younger than 15 years who underwent the following interventions or surgical operations?

Airway examination with flexible endoscopy

20. In your clinic, how many cases were there in a year that involved patients younger than 15 years who underwent the following interventions or surgical operations?

Elective or Emergency Tracheotomy

21. In your clinic, how many cases were there in a year that involved patients younger than 15 years who underwent the following interventions or surgical operations?

Head neck mass excision

22. In your clinic, how many cases were there in a year that involved patients younger than 15 years who underwent the following interventions or surgical operations?

Direct laryngoscopy

23. In your clinic, how many cases were there in a year that involved patients younger than 15 years who underwent the following interventions or surgical operations?

Endoscopic or open airway surgery

24. In your clinic, how many cases were there in a year that involved patients younger than 15 years who underwent the following interventions or surgical operations?

Otoplasty

25. In your clinic, how many cases were there in a year that involved patients younger than 15 years who underwent the following interventions or surgical operations?

Middle ear surgery

\begin{tabular}{|l|l|}
\hline None \\
\hline $1-5$ \\
\hline $6-10$ \\
\hline 11 or more \\
\hline $1-5$ \\
\hline $6-10$ \\
\hline 11 or more \\
\hline None \\
\hline $1-5$ \\
\hline $6-10$ \\
\hline 11 or more \\
\hline None \\
\hline $1-5$ \\
\hline $6-10$ \\
\hline 11 or more \\
\hline None \\
\hline $1-5$ \\
\hline $6-10$ \\
\hline 11 or more \\
\hline None \\
\hline $1-5$ \\
\hline $6-10$ \\
\hline 11 or more \\
\hline None \\
\hline $1-5$ \\
\hline
\end{tabular}

